\title{
Digital Geoarchaeology: Bridging the Gap Between Archaeology, Geosciences and Computer Sciences
}

\author{
Christoph Siart, Markus Forbriger, and Olaf Bubenzer
}

\begin{abstract}
Modern archaeology increasingly crosses academic boundaries by combining different new methodologies in order to answer research questions about ancient cultures and their remains. Above all, the geosciences became an indispensable counterpart of archaeology and cultural heritage management. As to the investigation of past archaeological landscapes and palaeoenvironments, the term Geoarchaeology is commonly used, representing the utilization of traditional and the development of new geoscientific applications for archaeological purposes. In addition, computationally engaged research became absolute state of the art in modern archaeology, in geoscientific landscape reconstructions and in the deciphering of spatio-temporal interactions between man and nature. Despite this multidisciplinary constellation, the thematic and methodological overlap of humanities, natural sciences and informatics is frequently disregarded. It is beyond debate that multidisciplinary approaches, which especially emerge at the interface of adjacent subjects, substantially contribute to a better understanding of ancient landscapes, their forming processes and the resulting cultural heritage. They allow fusing complementary perspectives for the first time and therefore go far beyond unilateral research designs. Digital Geoarchaeology, which is to be established in this chapter as a new concept for the first time, can therefore be regarded as an intersection of disciplines that contributes to the consolidation of different academic perspectives. It represents a novel approach in terms of computer scientific methods combined with geoscientific know-how and archaeological expertise to multi-methodically investigate past humanenvironmental relationships. Accessing this multidisciplinary interface helps overcome potentially restricted, monodisciplinary perceptions and
\end{abstract}

C. Siart $(\bowtie) \cdot$ M. Forbriger • O. Bubenzer

Institute of Geography, Physical Geography, Heidelberg

University, Heidelberg, Germany

e-mail: qb120@uni-heidelberg.de; m.forbriger@gmail.

com; olaf.bubenzer@uni-heidelberg.de 
provides new forms of unbiased approaches for investigating the interplay of man and nature. Thus, closer collaboration and dialogue across disciplinary boundaries will offer promising prospects for future research at the human-environmental interface.

\section{Keywords}

Digital geoarchaeology • Geoarchaeology - Geoinformatics - Digital humanities - Human-environmental interactions - Digital methods • Cross-disciplinarity

\subsection{Introducing the Concept of Digital Geoarchaeology}

Modern archaeology increasingly crosses academic boundaries by combining different new methodologies in order to answer research questions about ancient cultures and their remains. On the one hand, this development is attributed to the fact that human impact and environmental conditions are more and more considered coherent within the context of integral landscape reconstructions. On the other hand, it is the substantial technological progress made during the last decades that fostered this progression. Above all, the geosciences became an indispensable counterpart of archaeology and cultural heritage management. As to the investigation of past archaeological landscapes and palaeoenvironments, the term Geoarchaeology (or Archaeometry, if with a broader natural scientific focus; see Reindel and Wagner 2009) is commonly used, representing the utilization of traditional and the development of new geoscientific applications for archaeological purposes. In general, this pertains to geographical investigations and field methods (analysis and dating of geoarchives, e.g. sediments, soils, landforms) or geophysical prospecting like earth resistivity tomography, ground penetrating radar and geomagnetics (Sarris et al. 2018; Theodorakopoulou et al. 2018). During the last 50 years, geoarchaeological research was strongly influenced by earth scientists, namely, by geomorphologists (Butzer 1964, 1982, 2008; Renfrew 1976; Gladfelter 1977; Hassan 1979;
Rapp and Hill 2006; for the history of the discipline, see Hill 2017), who focused on deciphering the stratigraphy, the formation or the preservation of an archaeological site, the development of the surrounding landscape and the potential influence of environmental conditions like climate on human behaviour and vice versa. However, an increasing number of disciplines became involved (e.g. biology, anthropology, history), so that Engel and Brückner (2014) define Geoarchaeology more comprehensively as "... the science that studies geo-bio-archives in an archaeological context by also considering historical and archaeological data sources in its synthesis. It mainly applies geoscience tools in order to reconstruct the evolution and use of former landscapes and ecosystems, with regard to the interactions between humans and their environment". Hence, when considering the prevailing view, Geoarchaeology sensu originali is generally regarded as an applied and primarily physically oriented subject in terms of methodology and technologies used. In analogy to the definition of Archaeometry by Wagner (2007), it represents the interface between geosciences and archaeology and aims at contributing to the solution of cultural-historical questions.

In contrast to this conventional perception, we intend to go one step further by also taking account of the digital dimension of humanenvironmental studies and thereby aim at highlighting the frequently disregarded thematic overlap of humanities, natural sciences and informatics (Fig. 1.1). As shown by practice, computationally engaged research became absolute state of the art in modern archaeology, in 
geoscientific landscape reconstructions and in the deciphering of spatio-temporal interactions between man and nature. For instance, areawide remote sensing based on satellite imagery proves to be of great value for identifying surface findings (Lambers 2018), laser scanning allows for capturing archaeological sites and findings in 3D (Hämmerle and Höfle 2018; Raun et al. 2018) and digital elevation models (DEM) ideally qualify for detecting zones of archaeological interest and for spatially analysing and predicting the relationships between different sites (Siart et al. 2013; Bubenzer et al. 2018; Knitter and Nakoinz 2018). GIS, geoinformatics and computer sciences, have also served as essential tools in cultural heritage management for many years, particularly with regard to protecting archaeological sites (e.g. Ioannides et al. 2014).

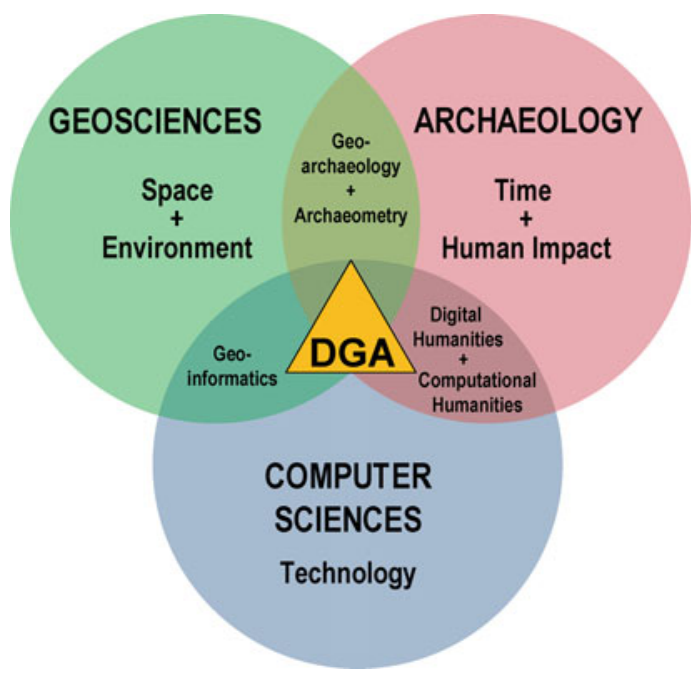

Fig. 1.1 The interdisciplinary intersection that defines the concept of Digital Geoarchaeology (DGA). While archaeology generally determines the historical context and the corresponding time slice, geosciences refer to the spatial and environmental dimension of studied objects. No less important is the use of computer-aided tools, particularly as to post-processing and fusion of archaeological and geoscientific datasets. This is why computer science functions as the technological backbone in DGA. Yet, all three domains are to be understood as equal and co-depending, even though each one may have a different share. Their methodological inventories can be combined in due respect of the scientific question to be unravelled (see Figs. 1.2 and 1.3 for details on workflow and applications of DGA)
Moreover, the permanent increase in spatial resolution of available datasets also helps to overcome the traditional problems of scale (e.g. Stein 1993; Schlummer et al. 2014) between archaeologists, who mainly work on specific and spatially restricted sites over distinct human-related time slices, and geoscientists, who rather focus on specific environments and/or landscape-forming processes. Given this broad spectrum of applications and new research designs, the rising impact of computer scientific, digital techniques on archaeological and palaeoenvironmental studies becomes evident.

\section{Presentation and Transfer}

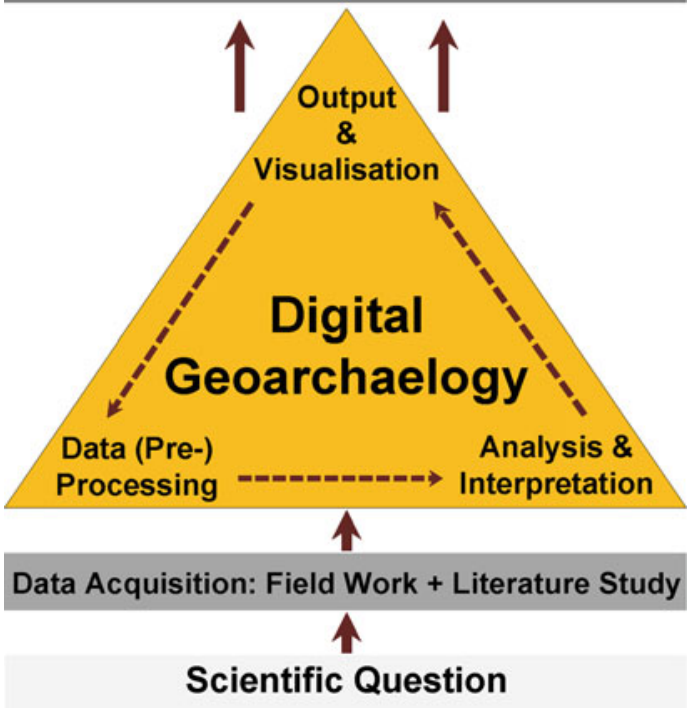

Fig. 1.2 Schematic workflow of Digital Geoarchaeology (modified according to Siart et al. 2013). Based on the topic to be investigated, which is mostly brought up by archaeology itself, acquisition of different datasets is carried out. Geosciences, computer sciences and archaeology come into play then, depending on the respective type of information required for solving specific scientific questions. The interdisciplinary interface (triangle) is characterized by data (pre-)processing in terms of desktop studies, analysis and subsequent interpretation of results, as well as final visualization (see Fig. 1.3 for details). This entire workflow is iterative and significantly relies on scholarly exchange. It leads to presentation and transfer of outcomes to both academia and the public - an aspect of special importance, e.g. for cultural heritage management and protection of archaeological sites, in which many different stakeholders are to be addressed with different levels of detail as to scientific outcomes 


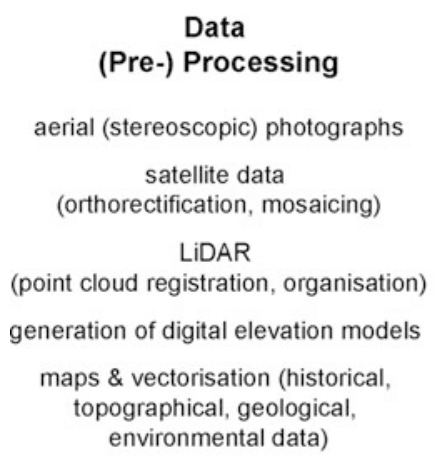

Data

(Pre-) Processing

aerial (stereoscopic) photographs

satellite data

(orthorectification, mosaicing)

LiDAR

(point cloud registration, organisation)

generation of digital elevation models

maps \& vectorisation (historical,

topographical, geological, environmental data)

Analysis \&

Interpretation

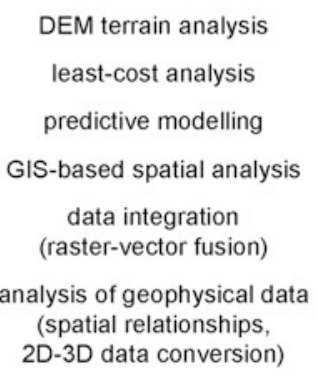

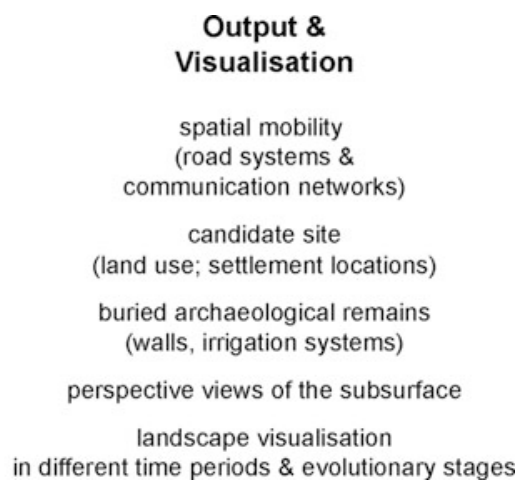

Fig. 1.3 Major work packages and examples of common procedures at the interdisciplinary interface of Digital Geoarchaeology

The multi-method overlap associated therewith could be described best using the term Digital Geoarchaeology (DGA, Fig. 1.1). Yet, when considering the status quo, comprehensive collaboration between archaeology, geosciences and informatics is still rare, even though useful synergies could be generated for all parties concerned. It is beyond debate that multidisciplinary approaches, which especially emerge at the interface of adjacent subjects, substantially contribute to a better understanding of ancient landscapes, their forming processes and the resulting cultural heritage. They allow fusing complementary perspectives for the first time and therefore go far beyond unilateral research designs.

Considering the common scientific discourse, the mutual benefits of integral research have not been fully explored yet. In fact, several similar trends and developments can be observed amongst different subjects, e.g. an increase of both the quantity and the quality of geoinformatic applications, but almost all of them happen separately within narrow disciplinary boundaries. In archaeology, for example, integration and consultation of geoscientific know-how is still the exception rather than the rule. This fact is mainly caused by the great progress archaeologists made themselves in using and developing further their own digital techniques over the last decades (Forte and Campana 2016). Digital Archaeology, a term that directly originates from this evolution (Zubrow 2006), describes these concepts best, but highlights at once that the initiatives are primarily driven by archaeologists and computer scientists without any input from earth sciences (Fig. 1.1). As almost every archaeological dataset is or can be georeferenced, and therefore owns a quintessential spatial attribute, allowance of profound geoscientific contribution could be an asset to better understand human-environmental interactions during specific time slices.

On the contrary, geoscientists generally need sound archaeological records to fully understand landscape evolution and natural processes in space and time. Now this is where the humanities represent a crucial component, because they help to identify the human impact and its historicocultural implications for the environment. The Working Group on Geoarchaeology of the International Association of Geomorphologists (IAG) and the German Working Group on Geoarchaeology (AK Geoarchäologie) as part of the German Society for Geography are only two examples, which illustrate the increasing significance of archaeological know-how in humanenvironmental research. However, both are predominantly driven by geomorphologists and only to a minor degree by archaeologists. Here, too, collaboration mostly corresponds to Geoarchaeology sensu originali, in which human impact on the environment is considered key, but joint research on the basis of digital applications is rare to non-existing. Vice versa, there are also several archaeological working groups with explicit foci on computationally 
engaged research, such as Computer Applications and Quantitative Methods in Archaeology (CAA) (AG CAA in Germany). Most of them are successfully promoted by archaeologists, mathematicians and computer scientists, whereas it is the geosciences that remain underrepresented despite similarities in research interests and applications.

Apart from the above-mentioned domains governed by either archaeology or the geosciences, it is essential to consider the viewpoint of scientific computing, which has also advanced into interdisciplinary spheres over the years. Computer scientific research is often linked to explicit archaeological and geospatial aspects, e.g. in the context of documentation of archaeological findings and the reconstruction of historical sites (Schäfer et al. 2012; Var et al. 2013; Bogacz et al. 2015) or photogrammetric image processing (Sauerbier 2013; Kersten et al. 2014). Referring to this, Bock et al. (2013) present a broad range of interdisciplinary studies and therefore introduce the term Computational Humanities. Unfortunately, the great potential and benefits of scientific computing still have not been fully explored as to geoarchaeological investigations, even though lots of innovative approaches could actually be transferred or adapted to other research questions. In common practice, initial project ideas for studies at the human-environmental interface do not originate from informatics. As the latter represents a very versatile, multipurpose discipline, overarching scientific questions must be developed by humanities or natural sciences, if humanenvironmental interactions are to be investigated (Fig. 1.2).

By analogy, this predominant unilateral view, in which geoscientific input is rather neglected, also applies to many topics that fall within the scope of Digital Humanities. They can be defined as transdisciplinary, computationally engaged research that brings digital tools and methods to the study of the humanities (Burdick et al. 2012), but following Bock et al. (2013), they differ from Computational Humanities as to their closer spectrum of concepts and methods applied as well as their stronger focus on information sciences.
To sum up and return to the starting point of this paper, Geoarchaeology sensu originali generally remains under the aegis of geoscientists, while Digital Archaeology or Computational Humanities are mainly pursued by archaeologists and computer scientists, respectively. All of the above-mentioned disciplinary interfaces (see also Fig. 1.1) have significantly evolved and developed their own spheres of activity during the last decades, but exchange with disciplinary counterparts was and still is uncommon. The major reason might be the different scholarly attitudes of natural sciences, computer sciences and humanities. Their prima facie distinct perceptions sometimes just originate from ignorance of actual parallels (e.g. with regard to research topics). Besides, attention must be paid to the fact that it is the methodological expertise that governs but also limits the execution of specific research. For instance, archaeologists and geoscientists gained profound IT experience over the years, but their knowledge is mostly very specific and does not necessarily compare to the actual scope of expertise of computer scientists (discrepancy between end users and developers).

Nevertheless, it is important to note, that within the framework of Digital Geoarchaeology, disciplines are meant to support each other and significantly interdepend. Geoscientific knowhow, for example, shall not substitute but promote archaeological studies as for methodologies and integration of spatial aspects (e.g. acquisition of appropriate geodata, use of specific techniques that help assess new archaeological archives like sediments). Geosciences may therefore improve the investigation and understanding of geoarchaeological landscapes and allow unravelling the palaeoenvironmental history comprehensively. In contrast, the historicocultural implications of measured values and geodata are not self-evident. They depend on thorough interpretation, which only evolves if close exchange between disciplines is ensured. In this regard, Maran (2007) points out the different levels of progress achieved amongst those humanities, which focus on the relationships of man and environment. While pre- and early history and earth sciences constantly approach each 
other and thereby integrate their viewpoints, archaeology is still prone to considering historical findings and geoscientific data in a juxtaposed and unlinked way.

In order to demonstrate the valuable synergies, which arise from interdisciplinary collaboration between humanities, natural sciences and informatics, the concept of Digital Geoarchaeology is to be promoted (Figs. 1.2 and 1.3). As shown by the current scholarly discourse, research interest is indeed often the same and similar scientific questions are to be answered. That is why each discipline involved can ultimately benefit from mutual knowledge transfer. Digital Geoarchaeology can therefore be regarded as an intersection of disciplines that contributes to the consolidation of different academic perspectives (Fig. 1.1). It represents a novel approach in terms of computer scientific methods combined with geoscientific know-how and archaeological expertise to multi-methodically investigate past human-environmental relationships. Accessing this multidisciplinary interface helps overcome potentially restricted, monodisciplinary perceptions and provides new forms of unbiased approaches for investigating the interplay of man and nature. Thus, closer collaboration and dialogue across disciplinary boundaries will offer promising prospects for future research at the human-environmental interface.

\section{References}

Bock H, Jäger W, Winckler M (eds) (2013) Scientific computing and cultural heritage. Contributions in computational humanities. Springer, Heidelberg

Bogacz B, Massa J, Mara H (2015) Homogenization of 2D \& 3D document formats for cuneiform script analysis. In: HIP 15 proceedings of the 3rd international workshop on historical document imaging and processing Gammarth, Tunisia - August 22-22, 2015. ACM, New York, pp 115-122

Bubenzer O, Bolten A, Riemer H (2018) In search of the optimal path to cross the desert. Geoarchaeology traces old trans-Saharan routes. In: Siart C, Forbriger M, Bubenzer O (eds) Digital geoarchaeology - new techniques for interdisciplinary human-environmental research. Springer, Heidelberg, pp 139-148

Burdick A, Drucker J, Lunenfeld P, Presner T, Schnapp J (2012) Digital humanities. Open access eBook. MIT Press, Cambridge, MA
Butzer KW (1964) Environment and archaeology: an introduction to Pleistocene geography. Aldine, Chicago

Butzer KW (1982) Archaeology as human ecology; method and theory for a contextual approach. Cambridge University Press, New York

Butzer KW (2008) Challenges for cross-disciplinary geoarchaeology: the intersection between environmental history and geomorphology. Geomorphology 101:402-411

Engel M, Brückner H (2014) Late Quaternary environments and society: progress in geoarchaeology. Z Geomorph N.F. 58(Suppl. 2):1-6

Forte M, Campana S (2016) Digital methods and remote sensing in archaeology. Archaeology in the age of sensing. Springer, Cham

Gladfelter BG (1977) Geoarchaeology: the geomorphologist and archaeology. Am Antiq 42(4):519-538

Hämmerle M, Höfle B (2018) Introduction to LiDAR in Geoarchaeology from a technological perspective. In: Siart C, Forbriger M, Bubenzer O (eds) Digital geoarchaeology - new techniques for interdisciplinary human-environmental research. Springer, Heidelberg, pp 167-182

Hassan FA (1979) Geoarchaeology: the geologist and archaeology. Am Antiq 44(2):267-270

Hill CL (2017) Geoarchaeology, history. In: Gilbert A (ed) Encyclopedia of geoarchaeology. Springer, Dordrecht

Ioannides M, Magnenat-Thalmann N, Fink E, Žarnić R, Yen A, Quak E (2014) Digital heritage. Progress in cultural heritage: documentation, preservation, and protection. In: Proceedings of 5th international conference, EuroMed 2014, Limassol, Cyprus, 3-8 Nov 2014. Springer, Cham

Kersten T, Hinrichsen N, Lindstaedt M, Weber C, Schreyer K, Tschirschwitz F (2014) Architectural historical 4D documentation of the old-segeberg town house by photogrammetry, terrestrial laser scanning and historical analysis. In: Ioannides M, MagnenatThalmann N, Fink E, Žarnić R, Yen A, Quak E (eds) Digital heritage. Progress in cultural heritage: documentation, preservation, and protection. Proceedings of 5th international conference, EuroMed 2014, Limassol, Cyprus, 3-8, Nov 2014. Springer, Cham, pp 35-47

Knitter D, Nakoinz O (2018) Point pattern analysis as tool for digital Geoarchaeology - a case study of megalithic graves in Schleswig-Holstein, Germany. In: Siart C, Forbriger M, Bubenzer O (eds) Digital geoarchaeology - new techniques for interdisciplinary humanenvironmental research. Springer, Heidelberg, pp 45-64

Lambers K (2018) Airborne and spaceborne remote sensing and digital image analysis in archaeology. In: Siart C, Forbriger M, Bubenzer O (eds) Digital geoarchaeology - new techniques for interdisciplinary human-environmental research. Springer, Heidelberg, pp 109-122

Maran J (2007) Mit den Methoden der Gegenwart in die Vergangenheit - Archäologie und 
Naturwissenschaften. In: Wagner GA (ed) Einführung in die Archäometrie. Springer, Heidelberg, pp $342-350$

Rapp GR, Hill CL (2006) Geoarchaeology: the earthscience approach to archaeological interpretation, 2nd edn. Yale University Press, New Haven

Raun K, Pfeiffer M, Höfle B (2018) Visual detection and interpretation of cultural remnants on the Königstuhl hillside in Heidelberg using airborne and terrestrial LiDAR data. In: Siart C, Forbriger M, Bubenzer O (eds) Digital geoarchaeology - new techniques for interdisciplinary human-environmental research. Springer, Heidelberg, pp 201-214

Reindel M, Wagner GA (2009) Introduction - new methods and technologies of natural sciences for archaeological investigations in Nazca and Palpa, Peru. In: Reindel M, Wagner GA (eds) New technologies for archaeology. Multidisciplinary investigations in Palpa and Nazca, Peru. Springer, Heidelberg

Renfrew C (1976) Archaeology and the earth sciences. In: Davidson DA, Shackley ML (eds) Geoarchaeology: earth science and the past. Westview Press, Boulder, pp 1-5

Sarris A, Kalayci T, Moffat I, Manataki M (2018) An introduction to geophysical and geochemical methods in digital geoarchaeology. In: Siart C, Forbriger M, Bubenzer O (eds) Digital geoarchaeology - new techniques for interdisciplinary human-environmental research. Springer, Heidelberg, pp 215-236

Sauerbier M (2013) Image-based techniques in cultural heritage modeling. In: Bock H, Jäger W, Winckler M (eds) Scientific computing and cultural heritage. Contributions in computational humanities. Springer, Heidelberg, pp 61-69

Schäfer A, Mara H, Freudenreich J, Breuckmann B, Düffort C, Bock G (2012) Large scale Angkor style reliefs: high definition $3 \mathrm{D}$ acquisition and improved visualization using local feature estimation. In: Zhou M, Romanowska I, Wu Z, Xu P, Verhagen P (eds) Revive the past. Proceedings of the 39th conference on computer applications and quantitative methods in archaeology, Beijing, 12-16 April. Pallas, Amsterdam, pp 70-80

Schlummer M, Hoffmann T, Dikau R, Eickmeier M, Fischer P, Gerlach R, Holzkämper J, Kalis AJ, Kretschmer I, Lauer F, Maier A, Meesenburg J, Meurers-Balke J, Münch U, Pätzold S, Steininger F, Stobbe A, Zimmermann A (2014) From point to area: upscaling approaches for late quaternary archaeological and environmental data. Earth Sci Rev 131:22-48

Siart C, Brilmayer Bakti B, Eitel B (2013) Digital Geoarchaeology - an approach to reconstructing ancient landscapes at the human-environmental interface. In: Bock H, Jäger W, Winckler M (eds) Scientific computing and cultural heritage. Contributions in computational humanities. Springer, Heidelberg, pp 71-85

Stein JK (1993) Scale in archaeology, geosciences, and geoarchaeology. In: Stein JK, Linse AR (eds) Effects of scale in archaeological and geoscientific perspectives. Geological Society of America, Boulder, Colorado, Special paper, vol 283, pp 1-10

Theodorakopoulou K, Bassiakos Y, Athanassas C, Schukraft G, Holzhauer I, Hecht S, Mächtle B, Wagner GA (2018) A geoarchaeological approach for the localization of the prehistoric harbor of Akrotiri, Thera. In: Siart C, Forbriger M, Bubenzer O (eds) Digital geoarchaeology - new techniques for interdisciplinary human-environmental research. Springer, Heidelberg, pp 237-252

Var P, Phal D, Nguonphan P, Winckler MJ (2013) 3D reconstruction of Banteay Chhmar temple for google earth. In: Bock H, Jäger W, Winckler M (eds) Scientific computing and cultural heritage. Contributions in computational humanities. Springer, Heidelberg, pp 261-272

Wagner GA (2007) Archäometrie in Heidelberg - ein Beispiel für das Werden eines neuen Faches. In: Wagner GA (ed) Einführung in die Archäometrie. Springer, Heidelberg, pp 351-366

Zubrow E (2006) Digital archaeology: a historical context. In: Evans T, Daly P (eds) Digital archaeology: bridging method and theory. Routledge, London, $\mathrm{pp}$ $10-31$

Open Access This chapter is licensed under the terms of the Creative Commons Attribution 4.0 International License (http://creativecommons.org/licenses/by/4.0/), which permits use, sharing, adaptation, distribution and reproduction in any medium or format, as long as you give appropriate credit to the original author(s) and the source, provide a link to the Creative Commons license and indicate if changes were made.

The images or other third party material in this chapter are included in the chapter's Creative Commons license, unless indicated otherwise in a credit line to the material. If material is not included in the chapter's Creative Commons license and your intended use is not permitted by statutory regulation or exceeds the permitted use, you will need to obtain permission directly from the copyright holder. 